\title{
Interactions of Commitment and Discretion in Monetary and Fiscal Policies
}

\author{
by \\ Avinash Dixit, Princeton University \\ and \\ Luisa Lambertini, UCLA* \\ Version 1.0 - August 2, 2000 \\ Final Version — June 5, 2003
}

\begin{abstract}
We consider monetary-fiscal interactions when the monetary authority is more conservative than the fiscal. With both policies discretionary, (1) Nash equilibrium yields lower output and higher price than the ideal points of both authorities, (2) of the two leadership possibilities, fiscal leadership is generally better. With fiscal discretion, monetary commitment yields the same outcome as discretionary monetary leadership for all realizations of shocks. But fiscal commitment is not similarly negated by monetary discretion. Second-best outcomes require either joint commitment, or identical targets for both authorities - output socially optimal and price level appropriately conservative - or complete separation of tasks. (JEL E61, E63)

Addresses of authors:

Avinash Dixit, Department of Economics, Princeton University, Princeton, NJ 08544-1021, USA. E-mail: dixitak@princeton.edu

Luisa Lambertini, Department of Economics, University of California, Los Angeles, CA 90095-1477, USA. E-mail: luisa@econ.ucla.edu
\end{abstract}

\footnotetext{
${ }^{*}$ We thank Lars Svensson and Robert Flood for useful suggestions. We also thank the editor in charge (Valerie Ramey) and three referees, whose comments have led to substantial improvements. Dixit thanks the National Science Foundation and Lambertini thanks the UCLA Senate for financial support.
} 


\section{Introduction}

There is a large body of literature that studies how a monetary authority will chose monetary policy under various assumptions about its objectives and the social welfare function. Robert J. Barro and David B. Gordon (1983), Kenneth Rogoff (1985a), Lars E. Svensson (1997) and the related literature suggest that governments should delegate monetary policy to a central bank that is instrument independent and appropriately conservative. A central bank is instrument independent if it has full control over the instruments of monetary policy; by appropriately conservative, this literature means that the central bank's output and/or inflation targets should be lower than the socially optimal ones and that the central bank should put more weight on inflation stabilization and less on output stabilization than society does. Central bank independence and conservatism eliminate the inflation bias of monetary policy that results from the incentive to exploit surprise inflation to raise output in the short run above its natural level, which is typically assumed to be inefficiently low.

This literature does not consider fiscal policy, implicitly assuming it to be fixed or passive. However, the authorities and procedures for the making of fiscal and monetary policies interact in reality, and these interactions can lead to very different macroeconomic outcomes than those predicted by the analysis of one policy in isolation. The fiscal authority (the finance ministry or the legislature) may not share the conservatism of the central bank. Moreover, one or both of these policies may have full discretion to respond to economic shocks, or may be committed in advance to specific response rules. If one policymaker follows a response rule while the other has discretion, then the latter's preferences may lead him to use his discretion to undermine the former's commitment; the former will foresee this discretionary response and that will affect its own choice of commitment. In this paper we study such interactions between monetary and fiscal policies.

We assume that the fiscal authority's objective is the social welfare function, and that the monetary authority has instrument independence in pursuing its delegated conservative objective. Each chooses its action individually; therefore their interaction becomes a noncooperative game. Depending on the structure of the game, this may yield a Nash or a leadership equilibrium, either with commitment to a policy rule or discretionary actions after economic shocks are realized. These noncooperative equilibria can be suboptimal.

We model an economy with monopolistic competition and nominal rigidities. ${ }^{1}$ Monopoly power over the produced good makes output inefficiently low and gives policymakers an incentive to use their policies to raise production in equilibrium. Fiscal policy, in the form of a production subsidy, increases the supply of goods and can achieve the efficient level of output. If fiscal policy creates deadweight losses, it would not be socially optimal to subsidize production to its efficient level. This leaves an output gap that policymakers wish to close with unanticipated policies. An unanticipated monetary expansion raises output and the price level because of staggered prices; an unanticipated supply-side fiscal policy, such as a production subsidy, increases the supply of goods and it may also lower private demand and prices if financed by per-head taxation. These economic effects interact through the strategic

\footnotetext{
${ }^{1}$ We follow Michael Woodford (2002) and the related literature.
} 
choices of the two authorities.

Our main findings are as follows:

1. If neither type of policy has commitment or leadership, the interaction between a conservative central bank in the sense of Rogoff (1985 a) and Svensson (1997) and a fiscal authority that maximizes social welfare leads to suboptimal and extreme outcomes. More precisely, the Nash equilibrium is not second-best; output is lower and the price level higher than what either authority wants. Time inconsistency makes fiscal policy too tight and monetary policy too loose, resulting in output being lower and prices being higher than optimal.

2. Giving leadership (first-mover advantage) to fiscal policy typically produces outcomes preferable to monetary leadership but not necessarily preferable to Nash from an exante perspective. Even the best-performing discretionary regime, however, is not second best.

3. The time-consistency problem of monetary policy can be solved by commitment to a rule specifying how the actual policy choice will respond to all possible realizations of the stochastic shocks. But with discretionary fiscal policy chosen by a strategic fiscal authority, the ex post reaction function of the fiscal authority acts as a constraint on the monetary rule. We find that this entirely negates the advantage of monetary commitment - the optimal monetary rule is no different than discretionary leadership of monetary over fiscal policy for every realization of the shocks. Thus fiscal discretion eliminates the gains of monetary commitment. Fiscal commitment, on the other hand, removes the excessive tightness of fiscal policy stemming from the desire to reduce deadweight losses and surprise expectations. Even though the ex post reaction function of the monetary authority constraints the fiscal rule, monetary discretion does not completely eliminate the gains of fiscal commitment.

4. Commitment achieves the second best only if it can be extended to both monetary and fiscal policy. Alternatively, commitment of fiscal policy with a conservative central bank in the sense of Rogoff (1985 a) and Svensson (1997) achieves the second best.

5. If commitment to a policy rule is not an option, the second best can be achieved by appropriately assigning goals to policies so as to avoid any conflict of objectives. Two alternative assignments are possible. First, the two authorities should have identical targets, the output target being the social optimum and the price target being conservative. Second, the two authorities should have separate targets, with the monetary authority caring only about the price level and the fiscal authority caring only about output net of deadweight losses. 


\section{Literature Review}

The large literature on commitment and discretion in monetary policy, initiated by Kydland and Prescott (1977) and Barro and Gordon (1983), assumes that distortions create shortrun benefits from unexpected inflation and studies the equilibria that arise under different institutional arrangements and their welfare properties. Typically, the first-best equilibrium can be achieved by eliminating the distortions; the second-best equilibrium can be achieved by commitment to a monetary policy rule; discretionary monetary policy leads to a fourthbest equilibrium. Improvements over discretion that lead to third- or even second-best equilibria can be obtained by delegation of monetary policy to a conservative central banker, as suggested by Rogoff (1985 a), or simple inflation targets, as suggested by Svensson (1997). An optimal central bank contract along the lines of Walsh (1995) and Persson and Tabellini (1993) can achieve the second best. All these works do not consider fiscal policy or simply assume it as exogenous. We study the equilibria of the game where the fiscal authority is a strategic player and show that commitment to a monetary policy rule fails to lead to the second-best allocation.

The literature on commitment and discretion in monetary policy considers additive stochastic shocks and studies linear monetary policy rules; one exception is Persson and Tabellini (1993), which allows for a general stochastic structure and characterizes, but does not solve explicitly for the optimal monetary policy rule. We allow very general stochastic shocks to the parameters, and find the fully optimal monetary policy rule as a nonlinear function of these shocks.

Our paper is related to three analyses of the interaction of monetary and fiscal policies. [1] Alesina and Tabellini (1987) consider a one-country model where the monetary authority chooses the inflation rate and the fiscal authority chooses the tax rate to finance government expenditures; both authorities have identical, explicit goals for inflation, output and the level of government expenditures but different tradeoffs among the goals. They find that monetary commitment might not be welfare improving when the two authorities assign different weights to their goals because the reduction in seignorage induces higher taxes (in order to achieve the public spending target) and lower output, which can more than compensate the gain stemming from lower inflation. Our paper differs from Alesina and Tabellini (1987) in several respects. First, we concentrate on the stabilization of the price level and output, and therefore abstract from government-spending targets. Second, and most importantly, when they briefly consider the case with no government spending target, their model does not have a time-consistency problem, so that output and inflation are at their targeted levels. Third, the two authorities have identical targets but possibly different weights for them in Alesina and Tabellini; we allow for the more general case where not only weights but also objectives are more conservative for the central bank. [2] Debelle and Fischer (1994) consider the case where the monetary authority has no explicit preferences about the level of public expenditures and consider Nash and Stackelberg equilibria, but do not consider state-contingent monetary rules. [3] Banerjee (1997) uses a model similar to ours in many respects. But first he considers only the pure time-consistency problem in a 
non-stochastic environment, and when later he introduces two additive stochastic shocks, allows only policy commitments to fixed numbers rather than any state-contingent rules, linear or otherwise.

Dixit and Lambertini (2000 a, 2001) consider two related models for the case of a monetary union. In these models, there is no time-consistency problem of monetary policy; the first work considers a special case where the ideal points of all countries' fiscal authorities and the common central bank coincide; then the ideal outcomes can be achieved despite any disagreements about tradeoffs between the objectives and for any order of moves. The second paper considers the case of conflicting objectives between the fiscal authorities and the common central bank in a monetary union when the preferences of the fiscal authorities are exogenously given; it finds that the interaction of monetary and fiscal policies leads to extreme output and inflation outcomes. The contribution of this paper above Dixit and Lambertini (2001) is that it considers explicitly the case of time-inconsistent monetary and fiscal policies and carries out a welfare analysis of the interaction of monetary and fiscal policies when the authorities have conflicting objectives.

Our work shows that if both monetary and fiscal policies have a time-consistency problem, making the monetary, but not the fiscal, authority conservative may make things worse. The general idea behind our result - reminiscent of the second best theory - is present in other works on policymaking with multiple strategic interactions. Rogoff (1985 b) and Kehoe (1989), for example, show that cooperation between two governments with an incentive toward time-inconsistent behavior may reduce welfare as lack of policy cooperation acts as a disciplining device.

\section{The Model}

The structural model underlying our analysis has monopolistic competition and staggered prices. Output is suboptimally low because of the monopolistic power of firms. Fiscal policy consists of a production subsidy financed by per-head taxes, which counters the monopoly distortion, and therefore fits most naturally with the structure of the model; fiscal policy, however, generates deadweight losses. Unanticipated monetary policy changes have real effects because of staggered price-setting. Log-linearization around the steady state yields our working model consisting of equations (1) and (2) below; it is like the Barro-Gordon (1983) model extended to include fiscal as well as monetary policy. The details of the structure are in Appendix A. ${ }^{2}$

There are two policymakers in the country: the central bank and the fiscal authority. The central bank chooses a policy variable $m$, which stands for some actual policy variable such as the base money supply or a nominal interest rate, and determines a component of the price level; thus higher $m$ means a more expansionary monetary policy. The fiscal authority chooses a policy variable $x$; a larger $x$ means a larger subsidy and a more expansionary fiscal policy.

\footnotetext{
${ }^{2}$ Available at http://econweb.sscnet.ucla.edu/lambertini/papers/appendix.pdf
} 
These policies affect the GDP level $y$ and the price level $\pi$ in the country. Let $\pi^{e}$ denote the private sector's rational expectation of $\pi$. We assume that the real GDP $y$ of the country is given by

$$
y=\bar{y}+a x+b\left(\pi-\pi^{e}\right),
$$

and the price level $\pi$ is given by

$$
\pi=m+c x .
$$

The explanation of the parameters in the output equation (1) is as follows: [1] $\bar{y}$ is the natural rate of output without any fiscal policy; this is suboptimally low because of monopolistic competition. [2] The scalar $a$ is the direct effect of fiscal policy on GDP. A production subsidy counters the monopoly distortion and has an expansionary effect on GDP; hence $a>0$. [3] The last term on the right-hand side of equation (1) is the usual supply effect of an unexpected increase in the price level; thus $b>0$. All these parameters are derived within the structural model of Appendix A.

Turning to equation (2), the price level is a sum of the component $m$ which is the controlled part of monetary policy or its initial stance, and a further contribution arising from fiscal policy. A production subsidy that raises the supply of goods and services reduces prices; hence, $c<0$. The overall effect of fiscal policy on output, $a+b c$, is positive as long as the deadweight losses from fiscal policy are not too large. ${ }^{3}$

The social loss function representing the losses of the representative agent is given by

$$
L_{F}=\frac{1}{2}\left[\left(\pi-\pi_{F}\right)^{2}+\theta_{F}\left(y-y_{F}\right)^{2}+2 \delta x\right] .
$$

This social loss function is derived in Appendix $\mathrm{B}^{4}$ on the basis of our microfounded model. $\pi_{F}$ is the average level of the pre-set prices in the economy and it is socially optimal to minimize price level dispersion. The GDP that minimizes social losses is such that $y_{F} \geq \bar{y}$ and extra output is desirable. Fiscal policy can raise output above its natural rate, but it creates deadweight losses $\delta>0$ in doing so. $\theta_{F}>0$ parameterizes the social preference for the output versus the price-level goals.

Fiscal policy is chosen by a fiscal authority that minimizes the social loss function (3). Monetary policy is chosen by a monetary authority that is conservative in a way that encompasses both Rogoff's and Svensson's definition, and minimizes a loss function

$$
L_{M}=\frac{1}{2}\left[\theta_{M}\left(y-y_{M}\right)^{2}+\left(\pi-\pi_{M}\right)^{2}\right],
$$

where $y_{M}$ is the output target, $\pi_{M}$ the price target and $\theta_{M}$ the preference for the output versus the prive-level goals for the monetary authority. The central bank is more conservative than society in the sense that $\theta_{M} \leq \theta_{F}$ and/or $\pi_{M} \leq \pi_{F}, y_{M} \leq y_{F}$.

\footnotetext{
${ }^{3}$ The model in Appendix A considers one specific kind of fiscal policy. But equations (1) and (2) can be interpreted as the reduced form arising from other types of fiscal policies, such as government spending to purchase goods or a supply-side fiscal policy financed by distortionary income taxes. The algebra is unchanged but the interpretations of the parameters $a, b$ and $c$ and their signs and values can differ. The working paper version, Dixit and Lambertini (2000 b), discusses such cases.

${ }^{4}$ Available at http://econweb.sscnet.ucla.edu/lambertini/papers/appendix.pdf
} 
The natural rate of output $\bar{y}$, the scalar parameter $a$ summarizing the fiscal policy effect on GDP, the scalar parameter $b$ for the supply effect of unexpected price changes, the scalar parameter $c$ of the effect of fiscal policy on the price level, the scalar parameter $\delta$ for the deadweight loss of fiscal policy, the scalar parameter $\theta_{F}$ for the social preferences, the efficient level of output $y_{F}$, the central bank's output target $y_{M}$ and price-level target $\pi_{M}$ and the scalar parameter $\theta_{M}$ for the central bank's preferences, are all stochastic shocks because they depend on the three stochastic preference parameters of the underlying structural model of Appendix A and B. We denote the whole vector of these shocks by $z=\left(\bar{y}, a, b, c, \delta, \theta_{F}, y_{F}, y_{M}, \pi_{M}, \theta_{M}\right) . \pi_{F}$, the level of pre-set prices, is chosen before $z$ is realized and is therefore non-stochastic. The policy variables $m$ and $x$ are implemented after the shocks are observed, and therefore are written as functions $m(z)$ and $x(z)$ (although the functional form may be fixed before the shocks are observed in regimes where policies are precommitted). The resulting outcomes of GDP and price are then also realization-specific or functions $y(z)$ and $\pi(z)$.

The literature in this area usually considers only linear policy rules - it restricts the form of the function $m(z)$ to be linear, and then finds the optimal values of the coefficients in this function. Since linear rules are not in general optimal, it becomes necessary to restrict the stochastic shocks; only additive shocks like our $\bar{y}$ are considered. Our stochastic structure is richer and we allow $m(z)$ and $x(z)$ to be arbitrary, and find the fully optimal rules.

The private sector's expectations are formed before any of these shocks are realized and before the policy variables are chosen; they do not depend on $z$. Thus equations (1) and (2) may be written with the $z$ arguments as

$$
y(z)=\bar{y}+a x(z)+b\left(\pi(z)-\pi^{e}\right),
$$

and

$$
\pi(z)=m(z)+c x(z) .
$$

To simplify the notation, we drop the dependence of output, price level and the policy variables on $z$ whenever it does not create confusion.

The condition of rational expectations is

$$
\pi^{e}=E_{z}[\pi(z)] \equiv \int \pi(z)
$$

where the integral is taken over the distribution of $z$, and is three-dimensional since all the components of $z$ are shown in Appendix A to be functions of three underlying structural parameters.

We will consider various possible policy regimes. In absence of commitment, the two policies may be simultaneous (Nash) or one of them may be first (leadership). If monetary policy is precommitted, then it has leadership with respect to setting the rule, and fiscal policy is the follower in each state of the world (realization of the shocks); if fiscal policy is precommitted, it has leadership with respect to setting the rule, and monetary policy is the follower in each state of the world. There is no conclusive evidence about the correct choice 
from among the possibilities. It may be argued on the one hand that the central bank's reputational considerations give it an advantage in making and keeping commitments, and on the other hand that the lags in fiscal policy enable commitment there. Similar conflicting arguments can be made for the order of moves under discretion. Therefore we consider all possibilities.

Hence, the timing of events is as follows:

1. We consider three possible scenarios of commitment:

(a) If there is joint commitment of the two policies, this is done in a coordinated manner using the fiscal authority's objective function, which coincides with social welfare.

(b) If the fiscal policy regime is one of commitment, the fiscal authority chooses its policy rule $x=x(z)$; this specifies how it will respond to the stochastic shocks. If the fiscal regime is one of discretion, nothing happens at this step.

(c) If the monetary policy regime is one of commitment, the central bank chooses its policy rule $m=m(z)$. If the monetary regime is one of discretion, nothing happens at this step.

2. The private sector forms expectations $\pi^{e}$.

3. The stochastic shock vector $z$ is realized.

4. (a) If the monetary policy regime is one of discretion, the central bank chooses $m$. If the monetary regime is one of commitment, the central bank simply implements the monetary rule $m$ that was chosen at step 1.

(b) If the fiscal regime is one of discretion, the fiscal authority chooses fiscal policy $x$. If the fiscal regime is one of commitment, the fiscal authority simply implements the fiscal rule $x$ that was chosen at step 1 .

When monetary and fiscal policies are discretionary, the relative timing of step 4 (a) and 4 (b) raises some questions. In fact, monetary and fiscal policies may be chosen simultaneously or their order may be reversed.

We proceed to consider the different cases of commitment and sequence of moves.

\section{Joint Commitment}

First we study the equilibrium with commitment of monetary and fiscal policy. Joint commitment delivers the socially optimal and feasible allocation; hence, it is the natural benchmark against which to compare all other equilibria. 
Let both the monetary and fiscal authorities minimize the social loss function (3) and recognize the rational expectations constraint. At step 1 the two authorities choose the whole functions $m(\cdot), x(\cdot)$ to minimize the expected loss function

$$
\int L_{F}(z)=\frac{1}{2} \int\left[\left(\pi(z)-\pi_{F}\right)^{2}+\theta_{F}\left(y(z)-y_{F}\right)^{2}+2 \delta x(z)\right] .
$$

The substitution of $\pi^{e}$ into the objective complicates the algebra, because it then involves one integration inside another. We avoid this by regarding the authorities as if they had another choice variable, namely $\pi^{e}$, but their choice was subject to the constraint (5). The common Lagrangean for this problem is as follows:

$$
\mathcal{L}_{\mathcal{F}}^{\mathcal{F} \mathcal{C}}=\int\left\{\frac{1}{2}\left[\theta_{F}\left(y(z)-y_{F}\right)^{2}+\left(\pi(z)-\pi_{F}\right)^{2}+2 \delta x(z)\right]+\lambda \pi(z)\right\}-\lambda \pi^{e},
$$

where $\lambda$ is the Lagrangean multiplier. The first-order condition with respect to the function $x(z)$ is given by

$$
\left(\pi(z)-\pi_{F}+\lambda\right) c+\theta_{F}(a+b c)\left(y(z)-y_{F}\right)+\delta=0 .
$$

The first-order condition with respect to the function $m(z)$ is given by

$$
\left(\pi(z)-\pi_{F}+\lambda\right)+\theta_{F} b\left(y(z)-y_{F}\right)=0 .
$$

The first-order condition with respect to $\pi^{e}$, after using (9), is given by

$$
-\lambda+\int\left(\pi(z)-\pi_{F}+\lambda\right)=0 .
$$

The fully optimal, nonlinear rules for monetary and fiscal policies imply ${ }^{5}$

$$
\pi(z)=\pi_{F}+\frac{\delta b}{a}-\int \frac{\delta b}{a}, \quad \pi^{e}=\pi_{F}, \quad y(z)=\tilde{y}=y_{F}-\frac{\delta}{a \theta_{F}}, \quad \lambda=\int \frac{\delta b}{a} .
$$

Much of the literature on monetary rules has imposed a condition of linearity so $m(z)$ is a linear function of the stochastic shocks and then calculated the expected loss and minimized it with respect to the coefficients of the linear function. We do not require linearity and solve a more general calculus of variations problem. Our monetary and fiscal rules are not a linear function of $z$, and the reason is that even though the model is linear-quadratic, our stochastic shocks are not in general additive. If $\delta=0$, full commitment delivers the first best allocation

$$
y=y_{F}, \quad \pi=\pi_{F} .
$$

If there are no deadweight losses from fiscal policy, i.e. $\delta=0$, the optimal subsidy eliminates the inefficiency stemming from monopolistic competition. Output and the price level are at the first-best levels.

\footnotetext{
${ }^{5}$ To be precise, our fully optimal rules should be written as $m\left(z, \pi_{F}, E_{z}[\delta b / a]\right), x\left(z, \pi_{F}, E_{z}[\delta b / a]\right)$, as can be inferred from equation (11). To keep our notation simple, we have dropped the dependence of precommitted monetary and fiscal rules from $\pi_{F}$ and $E_{z}[\delta b / a]$ and we refer to them with $m(z), x(z)$; conversely, we refer to discretionary monetary and fiscal policies with $m, x$.
} 
With deadweight losses from fiscal policy, i.e. $\delta>0$, joint commitment yields the socially optimal and feasible allocation that we refer to as second best. At the second best, there is no upward bias in the price level, which is on average $\pi_{F}$; output is below its efficient level because expansionary fiscal policy generates losses; the output gap, $\delta /\left(a \theta_{F}\right)$, is higher the larger the deadweight losses $\delta$, the less important is output in social preferences $\theta_{F}$, and the smaller the direct impact of fiscal policy on output $a$.

The rational expectations constraint is binding when all the $m, x$ are chosen ex-ante optimally. More precisely, $\lambda$ is the average reduction in the price level achieved by full commitment. ${ }^{6}$ Intuitively, fiscal policy is more expansionary and monetary policy more contractionary under commitment, as the policy authorities know that any attempt to create a surprise increase in the price level is correctly anticipated by the private sector.

\section{Discretionary Policies and Nash equilibrium}

In this policy regime, after each realization of the stochastic shock vector $z$, the fiscal authority chooses $x$, taking $m$ as given, so as to minimize the loss function $L_{F}$; the monetary authority chooses $m$, taking $x$ as given, so as to minimize its loss function $L_{M}$. The two authorities act non-cooperatively and simultaneously; however, when their choices are made, the private sector's expectations $\pi^{e}$ are fixed. After completing the analysis of the policy equilibrium and economic outcome for an arbitrarily given state $z$, we can find $\pi^{e}$ from the rational expectations condition (5).

The first-order condition for fiscal policy is obtained by differentiating (3) with respect to $x$, recognizing the dependence of $\pi$ on $x$; this gives

$$
\theta_{F}\left(y-y_{F}\right)(a+b c)+c\left(\pi-\pi_{F}\right)+\delta=0,
$$

or

$$
\pi=\pi_{F}-\theta_{F}\left(\frac{a}{c}+b\right)\left(y-y_{F}\right)-\frac{\delta}{c} .
$$

This defines the reaction function of the fiscal authority (FRF) in the $(y, \pi)$ space. If required, one can obtain the reaction function in terms of the policy variables $(m, x)$ by substituting $y$ and $\pi$ into (12) using (1) and (2). Since $c<0$ and $a+b c>0$, the FRF is positively sloped in the $(y, \pi)$ space; its exact position depends on the realizations of the stochastic shocks.

The first-order condition for monetary policy is obtained by differentiating (4) with respect to $m$, which gives

$$
\theta_{M}\left(y-y_{M}\right) b+\left(\pi-\pi_{M}\right)=0
$$

or

$$
\pi=\pi_{M}-\theta_{M} b\left(y-y_{M}\right) .
$$

This defines the reaction function for the monetary authority (MRF) in the $(y, \pi)$ space. Since $b>0$, the MRF is always negatively sloped.

\footnotetext{
${ }^{6}$ In fact, $\delta b / a$ is the upward bias in the price level that arises with discretionary monetary and fiscal policies. This result is shown in section 5 .
} 


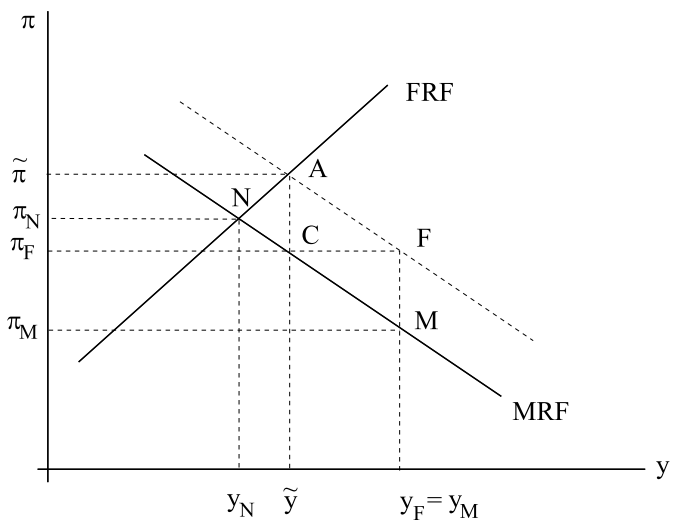

Figure 1: Nash Equilibrium

The Nash equilibrium outcomes $y$ and $\pi$ are found by solving (12), (13) and (5) together and the solution is given in Appendix C. Rational expectations imply $\pi^{e}=E[\pi]$ over the distribution of $z$, which is the expected value of the solution for $\pi$. Making use of (1) and (2) and $\pi^{e}=E[\pi]$, one can back out the policy variables $x$ and $m$ that emerge in equilibrium and deliver the Nash equilibrium outcomes for output and the price level. This is also done in Appendix C.

Figure 1 depicts the MRF (13) and the FRF (12) in the $(y, \pi)$ space. The MRF is the solid line through point $\mathrm{M}$, the bliss point for the conservative monetary authority; FRF is the solid line above point $\mathrm{F}$, the bliss point for society and for the fiscal authority. $\mathrm{F}$ is the first-best allocation that cannot be achieved in the presence of deadweight losses from fiscal policy: with $\delta>0$, FRF does not pass through point $\mathrm{F}$ because it is suboptimal to expand fiscal policy to reach $y_{F}$. The second best allocation is point $\mathrm{C}$ in Figure 1 , where $y=\tilde{y}<y_{F}$ and $\pi=\pi_{F}$. The Nash equilibrium occurs at the intersection of the two reaction functions $\mathrm{MRF}$ and FRF, and it is labelled N. We denote output and price at the Nash equilibrium by $\left(y_{N}, \pi_{N}\right) .^{7}$

We identify the following general characteristics of the Nash equilibrium:

$$
y_{N} \leq y_{M}<y_{F}, \quad y_{N} \leq \tilde{y}, \quad \pi_{N} \geq \pi_{F}>\pi_{M} .
$$

Only in the extreme special case where social welfare does not depend on the price level $\left(\theta_{F} \rightarrow \infty\right)$ will the Nash equilibrium be second-best $\left(y_{N}=\tilde{y}\right.$ and $\left.\pi_{N}=\pi_{F}\right)$. In the more general and realistic cases, both outcomes are more extreme than the ideal points of either policymaker: in the Nash equilibrium, output is lower and the price level higher than either policymaker want. Moreover, output is lower and the price level is higher in the Nash equilibrium, point $\mathrm{N}$, than at the second-best allocation, point $\mathrm{C}$.

The Nash equilibrium with a conservative central bank is extreme and suboptimal because of the time inconsistency of monetary and fiscal policies and their conflicting objectives.

\footnotetext{
${ }^{7}$ In drawing Figure 1, we have assumed that $\theta_{M}=\theta_{F}, y_{M}=y_{F}$ and $\pi_{M}=\pi_{F}-\delta b / a$, so that the MRF goes through the second-best allocation, point $\mathrm{C}$; the qualitative results, however, do not depend on these assumptions.
} 
Discretionary fiscal policy is less expansionary than committed fiscal policy. Once expectations are set, the government has an incentive to raise the price level so as to raise output. Since $c<0$, this is achieved by tightening fiscal policy. Monetary policy also suffers from time inconsistency: once expectations are set, monetary policy will be expanded so as to raise output. In a rational expectation equilibrium, these incentives are perfectly anticipated and there is no systematic output gain from surprises in the price level. Since fiscal policy is less expansionary and monetary policy more expansionary, output is lower and the price level higher in the Nash equilibrium than under full commitment.

If the central bank is not conservative and minimizes the loss function (3), then the MRF is the dotted line through the first best, point F in Figure 1. In this case, the Nash equilibrium has the following properties:

$$
y_{N}=\tilde{y}=y_{F}-\frac{\delta}{a \theta_{F}}, \quad \pi_{N}=\tilde{\pi}=\pi_{F}+\frac{\delta b}{a} .
$$

This is point A of Figure 1. The upward bias in the price level, $\delta /(b a)$, is higher the stronger the time-consistency problem of monetary (higher $b, \delta$ ) and fiscal policy (higher $a$ ).

Dixit and Lambertini (2000 a) consider the interaction between monetary policy of a common central bank and the separate fiscal policies of the member countries in a setting where monetary and fiscal policies do not have a time-consistency problem and the monetary authority has the same output and price goals as society, namely $y_{F}=y_{M}$ and $\pi_{F}=\pi_{M}$. It is shown that the socially optimal allocation is achieved without the need for commitment or fiscal coordination and irrespectively of which authority moves first. This intuition would carry through here: if there are no deadweight losses from fiscal policy, $\delta=0$, and both authorities' bliss points coincide with $\mathrm{F}$, then FRF and MRF go through $\mathrm{F}$ and deliver the first-best allocation as the Nash equilibrium. ${ }^{8}$

\subsection{Discretionary Monetary Policy with Non-Strategic Fiscal Pol- icy}

Barro and Gordon (1983), Rogoff (1985 a) and Svensson (1997) assume that fiscal policy is either absent or chosen non-strategically before the monetary authority acts. We briefly restate these results using the notation and techniques of our approach, to illustrate how our analysis stands apart from that literature. Suppose the fiscal authority is non-strategic and it either chooses the rule $\bar{x}(z)$ at stage 1 , or the policy $\bar{x}$ at step 4 (b), without taking into account the central bank's behavior. We can redefine the natural rate of output including fiscal policy as

$$
\hat{y}=\bar{y}+a \bar{x} .
$$

The fiscal policy $\bar{x}$ can be the rule arising from full commitment and such that $\hat{y}=\tilde{y}$ or just any other policy, for example $\bar{x}=0$ for all realization of the vector of shocks $z$; the

\footnotetext{
${ }^{8}$ Intuitively, a non-distortionary sale subsidy $(\delta=0)$ is a sufficient instrument to guarantee timeconsistency of monetary and fiscal policies if both authorities share output and price goals. See Hillier and Malcomson (1984).
} 
results below do not rely on any specific assumption. In terms of Figure 1, non-strategic fiscal policy makes the FRF a vertical line at $y=\hat{y}$.

Let the monetary authority minimize the social loss function (3) subject to $x=\bar{x}$; the first-order condition for monetary policy gives

$$
\pi=\pi_{F}-\theta_{F} b\left(y-y_{F}\right)
$$

This is the dotted line through point F in Figure 1. The average price level in this economy is

$$
\int \pi=\pi_{F}-\int \theta_{F} b\left[\hat{y}+b\left(\pi-\pi^{e}\right)-y_{F}\right],
$$

which is higher than $\pi_{F}$ as long as $\hat{y}<y_{F}$. In words, if the natural rate of output including fiscal policy is below efficiency, discretionary monetary policy generates higher-than-optimal prices because the central bank attempts to close the output gap via a surprise monetary expansion.

To eliminate the upward bias in prices, the monetary authority should commit to a rule, if feasible; we discussed this alternative in Section 7. Alternatively, Rogoff (1985 a) suggests to delegate discretionary monetary policymaking to a central bank with greater concern for the price level than society, while Svensson (1997) suggests delegation to a central bank with more conservative price target than society. The loss function (4) encompasses both Rogoff's and Svensson's definition of conservatism. For given $y_{M}, \theta_{M}, \bar{x}$, it is socially optimal to set the central bank's price target at

$$
\pi_{M}=\pi_{F}+\int \theta_{M} b\left(\hat{y}-y_{M}\right)
$$

so that the price level is on average equal to $\pi_{F}$ and output equal to $\hat{y}$.

If fiscal policy is strategic, an appropriately conservative central bank as in Rogoff and Svensson has price target

$$
\pi_{M}=\pi_{M}^{A C}=\pi_{F}+\int \theta_{M} b\left(\tilde{y}-y_{M}\right)
$$

for given $y_{M}, \theta_{M}$. This target ensures that the MRF is consistent with the second-best allocation and it goes through point $\mathrm{C}$ in Figure $1 .^{9}$

\section{Discretionary Policies and Leadership Equilibria}

Here we consider the case where both policies are discretionary, that is, chosen at step 4 without any commitment to a rule, but one of the policies is announced and fixed before the other, so one policymaker is the leader and the other the follower in the two-move subgame of step 4. It is not clear whether the timing of actions 4 (a) and 4 (b) should be as described

\footnotetext{
${ }^{9}$ Notice that the central bank is more price-conservative than the fiscal authority, i.e. $\pi_{M} \leq \pi_{F}$, as long as $y_{F} \geq y_{M} \geq \tilde{y}$ in (19).
} 
or the other way round. The current policy debate seems to assume that the central bank moves first and the fiscal authority follows; hence, the central bank may fear that subsequent fiscal expansions will bring the price level well above its goal. The literature on monetary unions, for example Beetsma and Bovemberg (1998), has argued that it takes a long time to change tax rates whereas monetary policy can be adjusted quite quickly; hence the timing of 4 (a) and (b) should be actually reversed. We consider both possibilities.

\subsection{Discretionary Policies and Monetary Leadership}

Here we consider the case of monetary leadership. Monetary policy is open to discretionary choice at step 4 (a); when fiscal policy is chosen at step 4 (b), $m$ is known. Private sector's expectations $\pi^{e}$ are set before and known when $m$ and $x$ are chosen.

Fiscal policy is exactly as described in section 5. The fiscal authority minimizes (3) with respect to $x$ taking $m$ and $\pi^{e}$ as given. Hence, the fiscal authority's reaction function is still described by (12).

The monetary authority minimizes the loss function (4) with respect to $m$. We can use (12) and the defining equations (1), (2) to solve for the fiscal response $x$ in terms of $m$, and substitute back into (1) and (2) to find $y$ and $\pi$ as functions of $m$ incorporating the fiscal reaction. But it is much easier equivalently to regard the monetary authority as choosing $y$ and $\pi$ directly, subject to the fiscal authority's reaction function (12) as a constraint. The first-order conditions for this Lagrangean problem are

$$
\begin{aligned}
\theta_{M}\left(y-y_{M}\right) & =\lambda_{M L} \theta_{F}(a+b c) \\
\pi-\pi_{M} & =\lambda_{M L} c
\end{aligned}
$$

where $\lambda_{M L}$ is the Lagrange multiplier. Combining these two, we have

$$
\theta_{M}\left(y-y_{M}\right)-\theta_{F}(b+a / c)\left(\pi-\pi_{M}\right)=0
$$

or

$$
\pi=\pi_{M}+\frac{\theta_{M}}{\theta_{F}(b+a / c)}\left(y-y_{M}\right) .
$$

The outcome in this case is then found by solving the monetary first-order condition (20) and the fiscal reaction equation (12) jointly. This gives the solution for $y$ and $\pi$, whose derivation is spelled out in Appendix D.

All of this happens separately for each realization of the vector $z$ of stochastic shocks; thus all the magnitudes including the Lagrange multiplier $\lambda_{M}$ are functions of $z$. Finally, we can find $\pi^{e}$ by taking expectations using (5).

In terms of Figure 1, the first-order condition (20) defines a downward-sloping line, because $(a+b c)<0$ and $c>0$ imply $(b+a / c)<0$. The line passes through the point M. It can be that can be steeper or flatter than MRF depending on the realization of the stochastic parameters. Hence, in the monetary leadership equilibrium both output and prices can be either higher or lower than in the Nash equilibrium. 


\subsection{Discretionary Policies and Fiscal Leadership}

In this section we consider the case of fiscal leadership. After the private sector's expectations are set and the shocks are realized, the fiscal authority chooses $x$. With $x$ fixed, the monetary authority chooses $m$. As usual, we solve this game by backward induction. This requires starting with the last player that, in this case, is the monetary authority.

The monetary authority minimizes the loss function (4) with $x$ given; hence, the firstorder condition with respect $m$ is given by the MRF (13) of section 5 . The fiscal authority minimizes the loss function (3) with respect to $x$, subject to (13). The first-order condition for fiscal leadership is:

$$
\pi=\pi_{F}+\frac{\theta_{F}}{\theta_{M} b}\left(y-y_{F}\right)+\frac{\delta\left(1+\theta_{M} b^{2}\right)}{\theta_{M} b a} .
$$

The outcome is found by solving the MRF (13) and the fiscal first-order condition (21). This gives the solution for $y$ and $\pi$ that we derive in Appendix E.

The first-order condition (21) defines an upward sloping line passing through point A of Figure 1 that can be steeper or flatter than FRF depending on the realization of the stochastic parameters. Hence, fiscal leadership has either lower output and higher prices than Nash, or vice versa. Once private expectations are set, the fiscal authority will always prefer fiscal leadership over Nash. This is to say that, a fiscal authority with a time-inconsistency problem and first-mover advantage chooses the allocation along the MRF that minimizes social losses; since these allocations include the Nash equilibrium, fiscal leadership is necessarily preferred, at least weakly, over Nash from an ex-post point of view. From an ex-ante point of view, this is to say before private expectations are set, fiscal leadership need not be welfare-superior than Nash. In fact, if fiscal leadership has lower output and higher prices than Nash, social losses are higher under fiscal leadership. The next section provides an example.

\subsection{Welfare Comparison of Discretionary Regimes}

This section compares social welfare under the discretionary regimes (Nash, monetary and fiscal leadership) from an ex ante point of view. We wish to shed some light on whether, or under what conditions, a discretionary regime is ex-ante preferable to the others independently of the realization of the shocks.

We run a Monte Carlo simulation using the parameter values derived within the structural model of Appendix A and B. This connects the stochastic parameters of our reduced-form model, $z$, to the stochastic preference parameters of the structural model. More precisely, changes in the parameters of the structural model necessarily imply changes in the elements of $z$, which are jointly distributed. For the steady state, we calibrate our model using the parameter values typically used in the literature; these are summarized in Appendix F; also, see Gali (2001). We then assume preference shocks that deliver output fluctuations within the range of $+/-6 \%$ of steady-state output, which are roughly consistent with the fluctuations of U.S. output around a quadratic trend. ${ }^{10}$

\footnotetext{
${ }^{10}$ See Appendix $\mathrm{F}$ for details.
} 
Table 1 reports the outcome of our comparison among discretionary regimes. We take 4,000 random draws of the stochastic parameters of the structural model and, for the same draws, we simulate our economy under three different configurations of the central bank's preferences and two different values for the deadweight loss of fiscal policy. ${ }^{11}$ In Table $1, \mathrm{~N}$ stands for Nash, FL stands for fiscal leadership, ML stands for monetary leadership. For each pair of discretionary regimes, Table 1 reports two statistics. First, the average difference in social losses; the figure in parentheses is the associated $t$-statistic that indicates whether the difference is statistically significant or not. Second, the output-equivalent difference in welfare, which is the percentage increase in output in the worse-performing regime that is necessary to make social losses equal to those under the better-performing regime. ${ }^{12}$

For the benchmark calibration, we assume the central bank is price-conservative with price target as in (19), but with the same weight and target for output as the fiscal authority, namely $\theta_{M}=\theta_{F}$ and $y_{M}=y_{F}$. In our benchmark economy, prices are typically highest under fiscal leadership and lowest under monetary leadership; output is lowest under monetary leadership and highest under Nash. In welfare terms, Nash performs better than both monetary and fiscal leadership from an ex-ante point of view. This is to say that fiscal leadership dominates Nash after expectations are set, but not before expectations are set. Once expectations are set, the fiscal authority believes that a tight fiscal policy will raise output via an unexpected increase in the price level; hence, discretionary fiscal policy is suboptimally contractionary. When the fiscal authority leads, it anticipates the price-conservativeness of the monetary authority and runs an even tighter fiscal policy than under Nash; as a result, output is lower and the price level higher than under Nash in our benchmark economy.

Monetary leadership performs better than fiscal leadership but worse than Nash, especially when deadweight losses from fiscal policy are low. The reason why monetary leadership dominates fiscal leadership is that it reduces the price level. Intuitively, a conservative central bank with first-mover advantage knows that the fiscal authority has a higher price target than its own and therefore runs a tighter monetary policy than under Nash. A tighter monetary stance, however, elicits a tighter fiscal stance, reducing output and prices with respect to Nash. When $\delta$ is low and the price level is close to its socially optimal level, the welfare gains of a price reduction is outweighted by the welfare losses of output reduction.

Next we reduce the central bank's weight for output to one third of that of the fiscal authority, leaving everything else as in the benchmark economy. The average $\theta_{F}$ is 0.83 and the average $\theta_{M}$ is 0.28 . Since the price target for the central bank is still given by (19), its policies are consistent with second best: in terms of Figure 1, the central bank reaction functions, with or without leadership, become flatter but still go through point C. Monetary leadership is dominated by both Nash and fiscal leadership from an ex-ante perspective with welfare gains in the order of 0.2 to 0.3 percent of output, depending on

\footnotetext{
${ }^{11}$ More precisely, the average $\delta$ is $0.08 \%$ and $0.44 \%$, respectively; see Appendix $\mathrm{F}$ for details.

${ }^{12}$ More precisely, leaving prices and fiscal policy unchanged, we calculate: a) the certainty-equivalent level of output in the worse-performing regime; b) the certainty-equivalent level of output in the worse-performing regime that is necessary to make social losses equal to those in the best-performing regime. Table 1 reports the percentage difference between these two output measures.
} 


\begin{tabular}{|c|c|c|c|c|c|c|}
\hline \hline & \multicolumn{2}{|c|}{ FL vs N } & \multicolumn{2}{c|}{ FL vs ML } & \multicolumn{2}{c|}{ N vs ML } \\
\hline & $\begin{array}{c}\text { average } \\
\left(L_{F}^{N}-L_{F}^{F L}\right)^{*}\end{array}$ & $\begin{array}{c}\text { output } \\
\text { equiv }\end{array}$ & $\begin{array}{c}\text { average } \\
\left(L_{F}^{M L}-L_{F}^{F L}\right)^{*}\end{array}$ & $\begin{array}{c}\text { output } \\
\text { equiv }\end{array}$ & $\begin{array}{c}\text { average } \\
\left(L_{F}^{M L}-L_{F}^{N}\right)^{*}\end{array}$ & $\begin{array}{c}\text { output } \\
\text { equiv }\end{array}$ \\
\hline $\begin{array}{c}\text { Benchmark } \\
\text { low } \delta\end{array}$ & $\begin{array}{c}-13.3 \\
(-72.6)\end{array}$ & -0.1 & $\begin{array}{c}-6.9 \\
(-10.6)\end{array}$ & -0.007 & 6.5 & 0.007 \\
\hline $\begin{array}{c}\text { Benchmark } \\
\text { high } \delta\end{array}$ & -29.3 & -0.07 & -28.3 & -0.03 & 1 & 0.9 \\
\hline$\theta_{M}=\theta_{F} / 3$ & $-12.3)$ & & $(-5.9)$ & & $(0.2)$ & 0.001 \\
low $\delta$ & $(-188.8)$ & -0.14 & 188.6 & 0.16 & 222.5 & 0.19 \\
\hline$\theta_{M}=\theta_{F} / 3$ & 33.9 & 0.05 & 558.7 & 0.35 & 524.9 & 0.32 \\
high $\delta$ & $(14.2)$ & & $(34.8)$ & & $(32.7)$ & \\
\hline$\pi_{M}<\pi_{M}^{A C}$ & 915.8 & 0.16 & 297360 & 128.2 & 297270 & 128.2 \\
low $\delta$ & $(53)$ & & $(150)$ & & $(150)$ & \\
\hline$\pi_{M}<\pi_{M}^{A C}$ & -999.4 & -0.16 & 87090 & 8 & 88084 & 8.1 \\
high $\delta$ & $(-58.9)$ & & $(57)$ & & $(60)$ & \\
\hline \hline
\end{tabular}

Table 1: Welfare comparison among discretionary regimes. FL: fiscal leadership; N: Nash; ML: monetary leadership; SB: second best; $*: \times e^{6}$

the value of $\delta$. Interestingly, fiscal leadership welfare-dominates Nash when $\delta$ is high, but is welfare-dominated by Nash when $\delta$ is low. Three factors contribute to this result. First, a lower $\theta_{M}$ implies a higher $\pi_{M}$ - see equation (19). In words, a more weight-conservative central bank can afford to be less-price conservative, which eliminates some of the fiscal authority's incentive to tighten its policy. Second, the fiscal authority with first-mover advantage anticipates the central bank's weight-conservatism and responds to it with a more expansionary fiscal policy. Third, higher deadweight losses from fiscal policy worsen its timeinconsistency by lowering the parameter $c$ and making the FRF flatter in Figure 1. These three factors make fiscal policy more expansionary under fiscal leadership than Nash, thereby raising output, lowering prices and lowering social losses.

The last two rows of Table 1 consider the case where the central bank's price target is five percent lower than the level predicted by (19); the weight on the output target as well as the output target are as in the benchmark economy. The central bank is now excessively conservative in the sense that its reaction functions are inconsistent with the second best, i.e. they pass below point $\mathrm{C}$ of Figure 1. Fiscal leadership is the best-performing discretionary regime when $\delta$ is low while Nash is the best-performing discretionary regime when $\delta$ is high. Intuitively, both prices and output are low in this equilibrium because of the conservativeness of monetary policy; at the same time, fiscal leadership has higher prices and lower output than Nash. When the output gap not too large ( $\delta$ low), the welfare gains from an increase in the price level outweight the welfare losses from lower output, and vice versa when the output gap is large $(\delta$ high). Welfare losses are large under monetary leadership when the central bank is excessively conservative because prices and especially output are too low. Intuitively, excessive conservatism of the central bank and monetary leadership result in 
monetary policy being too tight, which in turn makes fiscal policy exceedingly tight.

The results of this section can be summarized as follows. Monetary leadership is typically the worst-performing discretionary regime because it generates low output. Nash and fiscal leadership, on the other hand, cannot be welfare-ranked as easily because their comparison depends on the interplay between central bank's preferences and the inefficiency of fiscal policy.

\section{Monetary Commitment}

So long as the monetary rule has been credibly committed to, it does not matter whether fiscal policy is chosen before or after the actual monetary policy action is taken at step 4 . The shocks are already realized, so the monetary action is fully predictable even if it has not been taken yet. The fiscal authority must act with this foreknowledge; therefore it is a follower even though its action may be taken earlier in calendar time. Thus questions such as whether fiscal lags are long are irrelevant given monetary commitment and fiscal discretion.

Since the monetary policy rule $m(z)$ is chosen at an earlier stage, its decision must be made using the logic of subgame perfectness that takes into account the action of the fiscal authority later on in the game. One would think that commitment to a full state-contingent monetary rule would allow the central bank to get close to its ideal outcome or, at least, to do better than the case where monetary policy is discretionary. It turns out that, as long as fiscal policy is discretionary, the monetary authority cannot improve upon the equilibrium that arises under monetary leadership with discretion. Hence, fiscal discretion destroys monetary commitment! As long as the central bank can move before the fiscal authority, commitment to a policy rule does not matter. The most that monetary commitment can achieve is to ensure the equivalent of first-mover advantage (if it exists) in the game at step 4.

Lately, much emphasis has been put on the importance of monetary rules to maintain inflation low and stable. This argument is thought to be particularly relevant for monetary unions, such as the EMU, where each government may engage in fiscal expansions to increase its own GDP expecting to pass the cost of its profligacy to other members in the form of higher inflation and interest rates. Our finding suggests that commitment to a monetary rule not accompanied by commitment to a fiscal rule is not enough.

To solve for the monetary rule chosen at step 1, we must use backward induction and start from the choice of fiscal policy at step 4 (b). The fiscal authority minimizes the loss function (3) with respect to $x$ with $m$ fixed. The first-order condition with respect to $x$ is, once again, the FRF (12). One can therefore solve for fiscal policy as a function of the stochastic shocks, the monetary rule and private sector's expectations by substituting (1) and (2) into (12), and then solve for output and price, as of step 1 and taking into account the choice of the fiscal authority. This is done in detail in Appendix G.

At step 1, the monetary authority chooses the whole function $m(\cdot)$ to minimize the expected loss function

$$
\int L_{M}(z)=\frac{1}{2} \int\left[\theta_{M}\left(y(z)-y_{M}\right)^{2}+\left(\pi(z)-\pi_{M}\right)^{2}\right]
$$


where $y(z), \pi(z)$ and $\pi^{e}$ are given by (G.6), (G.7), and (5) respectively. But the substitution of $\pi^{e}$ into the objective complicates the algebra, because it then involves one integration inside another. We avoid this by regarding the monetary authority as if it had another choice variable, namely $\pi^{e}$, but its choice was subject to the constraint (5). The Lagrangean for this problem is as follows

$$
\mathcal{L}_{\mathcal{M}}=\int\left\{\frac{1}{2}\left[\theta_{M}\left(y(z)-y_{M}\right)^{2}+\left(\pi(z)-\pi_{M}\right)^{2}\right]+\lambda_{M} \pi(z)\right\}-\lambda_{M} \pi^{e},
$$

where $\lambda_{M}$ is the Lagrangean multiplier.

The first-order condition with respect to the function $m(z)$ is given by

$$
\left(y(z)-y_{M}\right)-\frac{\theta_{F}}{\theta_{M}}\left(\frac{a}{c}+b\right)\left(\pi(z)-\pi_{M}+\lambda_{M}\right)=0 .
$$

The first-order condition with respect to $\pi^{e}$ is given by

$$
-\lambda_{M}-\int \frac{\theta_{M} b}{\theta_{F}\left(\frac{a}{c}+b\right)^{2}+1}\left[\left(y(z)-y_{M}\right)-\frac{\theta_{F}}{\theta_{M}}\left(\frac{a}{c}+b\right)\left(\pi(z)-\pi_{M}+\lambda_{M}\right)\right]=0 .
$$

Using (24), the first-order condition (25) simplifies to

$$
\lambda_{M}=0
$$

When all the $m$ are chosen ex-ante optimally, the rational expectations constraint is on the borderline of not binding. Using $\lambda_{M}=0,(24)$ becomes

$$
\left(y(z)-y_{M}\right)-\frac{\theta_{F}}{\theta_{M}}\left(\frac{a}{c}+b\right)\left(\pi(z)-\pi_{M}\right)=0,
$$

which is equivalent to (20), the first-order condition for $m$ in the case where monetary policy is discretionary with monetary leadership! In fact, the state-by-state outcomes can be found by solving the discretionary fiscal reaction function (12) and the monetary rule (26), which is done in Appendix D. The outcome under monetary commitment is therefore exactly the same as the outcome under monetary discretion with monetary leadership for every realization of the shocks.

In models where fiscal policy is non-strategic, as in section 5.1, monetary commitment eliminates the upward bias in prices without affecting output. This is not the case with strategic and discretionary fiscal policy: monetary commitment must lie on the fiscal reaction function, so that the reduction in prices (relative to what they are in the discretionary solution with monetary leadership) is necessarily accompanied by a reduction in output. Under fiscal discretion, the monetary authority, if it could commit, would have no incentive to pursue a policy any tighter than that chosen under discretion with monetary leadership. But, then, subject to the constraint (5), the monetary authority has no incentive to influence expectations (relative to what they are in the discretionary solution with monetary leadership) either. Thus, the Lagrangean multiplier on expectations is just equal to zero. 
Monetary commitment is irrelevant when fiscal policy is discretionary as long as the central bank does not internalize the distortions of fiscal policy. If the term $2 \delta x$ also appeared in the loss function of the central bank, the optimal monetary rule would recognize the time inconsistency of fiscal policy and pursue a tighter policy than that chosen under discretion with monetary leadership. In this case, monetary commitment would survive fiscal discretion: the Lagrangean multiplier of the rational expectations constraint would be different from zero and equal to the value it takes under joint commitment, i.e. $\lambda$ in equation (11).

This result has important implications for the optimal design of central banks. If commitment to a monetary rule is possible, the central bank should internalize the distortions of fiscal policy. Failure to do so makes monetary commitment irrelevant.

\section{Fiscal Commitment}

Now we consider the case where fiscal policy is committed at step 1 whereas monetary policy is discretionary and chosen at step 4 (a). Our exposition will be brief, since the logic by which the fiscal rule $x(z)$ is chosen is very much similar to that used in the previous section for monetary commitment.

The monetary authority minimizes the loss function (4) with respect to $m$ with $x$ fixed. The first-order condition with respect to $m$ is, once again, the MRF (13). Then, one can solve for monetary policy as a function of the stochastic shocks, the fiscal rule and private sector's expectations by substituting (1) and (2) into (13), and then output and the price level, as of step 1 and taking into account the choice of the monetary authority. This is done in detail in Appendix H.

The Lagrangean for the problem of the fiscal authority is as follows:

$$
\mathcal{L}_{\mathcal{F}}=\int\left\{\frac{1}{2}\left[\theta_{F}\left(y(z)-y_{F}\right)^{2}+\left(\pi(z)-\pi_{F}\right)^{2}+2 \delta x(z)\right]+\lambda_{F} \pi(z)\right\}-\lambda_{F} \pi^{e},
$$

where $\lambda_{F}$ is the Lagrangean multiplier, $y(z), \pi(z)$ and $\pi^{e}$ are given by (H.10), (H.11) and (5), respectively.

The first-order condition with respect to the function $x(z)$ is given by

$$
\left(y(z)-y_{F}\right) \frac{\theta_{F}}{\theta_{M} b}-\left(\pi(z)-\pi_{F}+\lambda_{F}\right)+\delta \frac{1+\theta_{M} b^{2}}{\theta_{M} b a}=0 .
$$

The first-order condition with respect to $\pi^{e}$ is given by

$$
-\lambda_{F}-\int \frac{\theta_{M} b^{2}}{1+\theta_{M} b^{2}}\left[\left(y(z)-y_{F}\right) \frac{\theta_{F}}{\theta_{M} b}-\left(\pi(z)-\pi_{F}+\lambda_{F}\right)\right]=0 .
$$

Using (28), the first-order condition (29) simplifies to

$$
\lambda_{F}=\int \frac{\delta b}{a}>0 .
$$




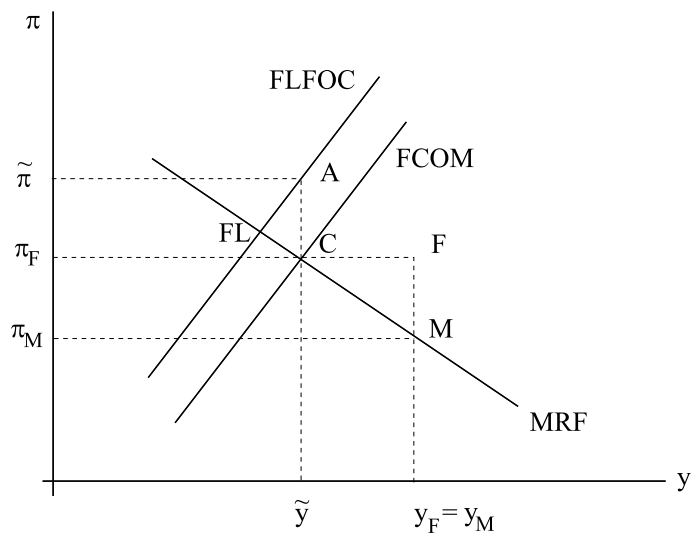

Figure 2: Fiscal commitment

Using (28), (13) and (30), one can solve for output and price; this is done in Appendix H.

Fiscal commitment is equivalent to fiscal leadership for all realization of shocks without time inconsistency of fiscal policy. The first-order condition with fiscal commitment (28) is the same as the first-order condition with fiscal leadership (21) except for the term $\lambda_{F}$. Figure 2 shows the equilibrium with fiscal commitment and that with fiscal leadership. FLFOC, the first-order condition with fiscal leadership, goes through point A; FCOM, the first-order condition with commitment, is parallel to FLFOC and shifted down by $\lambda_{F}$, the Lagrangean multiplier of the rational expectations constraint. $\lambda_{F}>0$ implies that the rational expectations constraint is binding when all the $x$ are chosen ex-ante optimally. More precisely, $\lambda_{F}$ is the average upward bias in prices that arises with fiscal leadership at $y=\tilde{y}$. Commitment of fiscal policy eliminates this bias, thereby shifting the first-order condition from FLFOC to FCOM. Notice that FCOM passes through point $\mathrm{C}$ and is therefore consistent with the second best.

An important result emerges here. If the central bank is appropriately conservative with price target as in (19), fiscal commitment delivers the second best. Figure 2 shows the MRF of such central bank, which goes through point $\mathrm{C}$; fiscal commitment occurs at the intersection of FCOM and MRF, which is point $\mathrm{C}$ and the second-best allocation.

Even though the fiscal authority is constrained to choose an allocation along the reaction function of the monetary authority, fiscal commitment is useful because it eliminates the excessive tightness of fiscal policy stemming from the desire to reduce deadweight losses and surprise expectations. Hence, monetary discretion does not destroy the gains of fiscal commitment.

\section{Institution Design and Welfare}

If commitment to a policy rule is not an option, could monetary and fiscal institutions be designed so as to obtain the second best with discretionary policies? The answer is yes. In our setting, there are two different goal assignments that lead to the second-best allocation. 
First, the monetary and fiscal authorities should be assigned identical goals. In the presence of a time-consistency problem of monetary and fiscal policies, the second best is obtained by giving the same socially optimal output objective and the same conservative price objective to both authorities. More precisely, the following loss function for both authorities:

$$
\tilde{L}_{F}=\frac{1}{2}\left[\left(\pi-\tilde{\pi}_{F}\right)^{2}+\theta_{F}\left(y-y_{F}\right)^{2}+2 \delta x\right],
$$

with

$$
\tilde{\pi}_{F}=\pi_{F}-\frac{\delta b}{a}
$$

achieves the second best as the Nash as well as any leadership equilibrium. Intuitively, price conservativeness takes care of the time-consistency problem of monetary and fiscal policies; at the same time, the fact that both authorities have identical objectives eliminates any suboptimal interaction between their policies. In terms of Figure 1, $\tilde{L}_{F}$ shifts the bliss point of the government from $\mathrm{F}$ to $\mathrm{M}$, so that the FRF goes through $\mathrm{C}$, which is the Nash equilibrium; in terms of Figure 2, with $\tilde{L}_{F}$ the FLFOC goes through C, which is the fiscal leadership equilibrium.

Alternatively, the second best can be achieved by a complete separation of goals between the two authorities. The central bank should target the price to be at its socially optimal level and minimize the loss function

$$
L_{M}^{*}=\frac{1}{2}\left(\pi-\pi_{F}\right)^{2} .
$$

Since $\pi_{F}$ is the average pre-set price level, (31) implies that the central bank should care only to minimize price disperson. With Nash or monetary leadership, the fiscal authority should minimize the loss function

$$
L_{F}^{* N}=\frac{1}{2}\left[\theta_{F}\left(y-y_{F}^{*}\right)^{2}+2 \delta x\right]
$$

where

$$
y_{F}^{*}=y_{F}-\frac{\delta b}{a \theta_{F}(a / c+b)}>y_{F}
$$

is the output target appropriately adjusted to counterbalance the contractionary bias of fiscal policy stemming from time inconsistency. In terms of Figure 1, under this goal assignment the MRF becomes the horizontal line $\pi=\pi_{F}$, the FRF becomes the vertical line $y=\tilde{y}$, and their intersection is point $\mathrm{C}$, which is the Nash and monetary leadership equilibrium.

Alternatively, if fiscal policy has leadership over monetary policy, the fiscal authority should minimize

$$
L_{F}^{* F L}=\frac{1}{2}\left[\theta_{F}\left(y-y_{F}\right)^{2}+2 \delta x\right] .
$$

The fiscal authority with first-mover advantage anticipates that any tightening of fiscal policy carried out to raise the price level and surprise expectations would be met by a tightening of monetary policy to bring the price level back to $\pi_{F}$. This eliminates the time-inconsistency of fiscal policy and makes the appropriate output target in (33) the socially efficient one. 


\section{Concluding Comments}

Any policy implications of such a simple first pass at a large problem must be tentative. With that proviso, we would like to suggest some implications of our results for the design of monetary and fiscal institutions.

If monetary and fiscal policies suffer from time-inconsistency, the non-cooperative game among them can result in a Nash equilibrium that is extreme in both the dimensions of output (low) and prices (high) because fiscal policy is too contractionary and monetary policy too expansionary. This outcome may have arisen in 1999-2000 in the newly formed Economic and Monetary Union of Europe (EMU); the U.S. experience of 1974-75, when tight fiscal policy and negative real interest rates lead to double-digit inflation and falling output, is another example.

Among the leadership equilibria, fiscal leadership is generally better. Nevertheless, fiscal leadership may be dominated by Nash from an ex-ante perspective and all discretionary equilibria, even the best-performing one, is not second best.

When policies can be chosen after stochastic shocks are realized, policymaking can be discretionary, or rule-governed in the sense of precommitment to a function that specifies the policy action to be taken as a function of the realization of the shock. The merits of commitment to a monetary rule are well understood from models that consider monetary policy in isolation. We find that if fiscal policy remains discretionary, then the monetary rule must recognize the fiscal reaction function as a constraint in each state of the world, with the result that the value of monetary commitment is completely negated - the optimal monetary rule is the same as monetary leadership in each state of the world (for each realization of the shocks). Therefore it may not be worth incurring the political cost of putting in place any mechanisms of monetary commitment, unless fiscal policy is also committed.

If fiscal policy is committed while monetary policy is discretionary, monetary discretion cannot offset the deadweight loss created by fiscal policy and therefore does not destroy fiscal commitment.

If the monetary and fiscal authorities' ideal point in the output-price space, and its tradeoff parameter between the two objectives, can be chosen in advance, then this choice can be made to affect the outcome point and the socially optimal and feasible allocation can be achieved by making both authorities equally and optimally conservative with respect to price level. Alternatively, the socially optimal and feasible allocation can be achieved by making the two authorities care about separate objectives, with the monetary authority target only the price level and the fiscal authority target only output net of deadweight losses. 


\section{Appendix}

\section{Nash equilibrium}

Written in matrix notation, we have

$$
\left[\begin{array}{cc}
\theta_{F}(b+a / c) & 1 \\
\theta_{M} b & 1
\end{array}\right]\left[\begin{array}{c}
y \\
\pi
\end{array}\right]=\left[\begin{array}{c}
\pi_{F}+\theta_{F}(b+a / c) y_{F}-\delta / c \\
\pi_{M}+\theta_{M} b y_{M}
\end{array}\right]
$$

The determinant of the matrix on the left hand side is

$$
\Omega \equiv \theta_{F}\left(\frac{a}{c}+b\right)-\theta_{M} b
$$

Then the solution exists as long as $\Omega$ is different from zero, which is the case almost surely (for probability one of realizations of shocks). The solution is given by

$$
\left[\begin{array}{l}
y \\
\pi
\end{array}\right]=-\frac{1}{\Omega}\left[\begin{array}{cc}
1 & -1 \\
-\theta_{M} b & \theta_{F}(b+a / c)
\end{array}\right] \times\left[\begin{array}{c}
\pi_{F}+\theta_{F}(b+a / c) y_{F}-\delta / c \\
\pi_{M}+\theta_{M} b y_{M}
\end{array}\right]
$$

Write (1) and (2) also in vector-matrix notation:

$$
\left[\begin{array}{cc}
a+b c & b \\
c & 1
\end{array}\right]\left[\begin{array}{c}
x \\
m
\end{array}\right]=\left[\begin{array}{c}
y-\bar{y}+b \pi^{e} \\
\pi
\end{array}\right]
$$

This has the solution

$$
\left[\begin{array}{c}
x \\
m
\end{array}\right]=\frac{1}{a}\left[\begin{array}{cc}
1 & -b \\
-c & a+b c
\end{array}\right]\left[\begin{array}{c}
y-\bar{y}+b \pi^{e} \\
\pi
\end{array}\right]
$$

The values of $x, m$ can then be obtained substituting $y, \pi$ from (C.1).

\section{Monetary Leadership}

Written in vector-matrix notation, we have

$$
\left[\begin{array}{cc}
\theta_{M} & -\theta_{F}(b+a / c) \\
\theta_{F}(b+a / c) & 1
\end{array}\right]\left[\begin{array}{c}
y \\
\pi
\end{array}\right]=\left[\begin{array}{c}
\theta_{M} y_{M}-\theta_{F}(b+a / c) \pi_{M} \\
\theta_{F}(b+a / c) y_{F}+\pi_{F}-\delta / c
\end{array}\right]
$$

This has the solution

$$
\begin{aligned}
& {\left[\begin{array}{c}
y \\
\pi
\end{array}\right]=\frac{1}{\theta_{M}+\theta_{F}^{2}(b+a / c)^{2}}\left[\begin{array}{cc}
1 & \theta_{F}(b+a / c) \\
-\theta_{F}(b+a / c) & \theta_{M}
\end{array}\right]} \\
& \times\left[\begin{array}{c}
\theta_{M} y_{M}-\theta_{F}(b+a / c) \pi_{M} \\
\theta_{F}(b+a / c) y_{F}+\pi_{F}-\delta / c
\end{array}\right]
\end{aligned}
$$

The values of $x, m$ can then be obtained substitituting from (D.3) in (C.2). 


\section{E Fiscal Leadership}

Written in vector-matrix notation, we have

$$
\left[\begin{array}{cc}
\theta_{M} b & 1 \\
-\theta_{F} & \theta_{M} b
\end{array}\right]\left[\begin{array}{c}
y \\
\pi
\end{array}\right]=\left[\begin{array}{c}
\theta_{M} b y_{M}+\pi_{M} \\
-\theta_{F} y_{F}+\theta_{M} b \pi_{F}+\delta\left(1+\theta_{M} b^{2}\right) / a
\end{array}\right]
$$

This has the solution

$$
\begin{gathered}
{\left[\begin{array}{c}
y \\
\pi
\end{array}\right]=\frac{\theta_{M} b}{\theta_{M}^{2} b^{2}+\theta_{F}}\left[\begin{array}{cc}
\theta_{M} b & -1 \\
\theta_{F} & \theta_{M} b
\end{array}\right]} \\
\times\left[\begin{array}{c}
\theta_{M} b y_{M}+\pi_{M} \\
-\theta_{F} y_{F}+\theta_{M} b \pi_{F}+\delta\left(1+\theta_{M} b^{2}\right) / a
\end{array}\right]
\end{gathered}
$$

\section{F Simulation}

Now we describe how we chose the parameter values for our benchmark economy; also, see the parametrization in Gali (2001). We assume $\beta=2$, which implies a unit wage elasticity of labor supply. $\gamma$ is set at 0.8 , which makes real money demand equal to $25 \%$ of consumption in the steady state and is roughly consistent with post-war U.S. real balances. The baseline choice for $\phi$ is 0.5 . Under the Calvo formulation, this value implies an average price duration of three quarters, which appears to be in line with econometric estimates of the parameter as well as with survey evidence. The elasticity of substitution $\theta$ is set to be 11 at the steady state, which is consistent with a $10 \%$ stead-state markup. $d$, the techonology parameter is set equal to 1 and the discount parameter $\eta$ is set equal to .98. The average of the pre-set prices $\pi_{F}$ is set equal to 100 . For the deadweight loss of fiscal policy, we consider two different specifications: $\alpha=0.005$ and $\alpha=0.001$, which imply that $0.5 \%$ and $0.1 \%$ of fiscal subsidies are wasted by the government.

Consistent with the model of Appendix A and B, we then assume the preference parameters $d, \theta, \beta$ are stochastic, i.i.d. with lognormal distribution with means as specified above. Their variances are calibrated to get output fluctuations in the range of $+/-6 \%$ of steadystate output, which are roughly consistent with the fluctuations of U.S. output around a quadratic trend.

\section{G Monetary Commitment}

Substituting (1) and (2) into (12), we obtain

$$
\begin{aligned}
x(z)= & \frac{1}{c\left[\theta_{F}(b+a / c)^{2}+1\right]}\left\{-\left[\theta_{F} b\left(\frac{a}{c}+b\right)+1\right] m(z)\right. \\
& \left.-\theta_{F}\left(\frac{a}{c}+b\right)\left[\bar{y}-y_{F}-b \pi^{e}\right]+\pi_{F}-\frac{\delta}{c}\right\} .
\end{aligned}
$$


Output and prices, as of step 1 and taking into account the choice of the fiscal authority at step $4(\mathrm{~b})$, are

$$
y(z)=\frac{1}{\theta_{F}(b+a / c)^{2}+1}\left\{-\frac{a}{c} m(z)+\bar{y}-b \pi^{e}+\theta_{F}\left(\frac{a}{c}+b\right)^{2}\left[y_{F}+\frac{\pi_{F}-\delta / c}{\theta_{F}(a / c+b)}\right]\right\},
$$

and

$$
\pi(z)=\frac{1}{\theta_{F}(b+a / c)^{2}+1}\left\{\theta_{F} \frac{a}{c}\left(\frac{a}{c}+b\right) m(z)-\theta_{F}\left(\frac{a}{c}+b\right)\left[\bar{y}-y_{F}-b \pi^{e}\right]+\pi_{F}-\frac{\delta}{c}\right\} .
$$

Proceeding by backward induction, we now consider the private sector that sets its expectations rationally at step 2. More precisely, expectations are

$$
\pi^{e}=\int \pi(z)
$$

with $\pi(z)$ given by (G.7) and the integral is four-dimensional with respect to the joint distribution of $z$.

\section{H Fiscal Commitment}

Substituting (1) and (2) into (13), we obtain

$$
m(z)=\frac{1}{1+\theta_{M} b^{2}}\left\{\pi_{M}-\theta_{M} b\left(\bar{y}-b \pi^{e}-y_{M}\right)-x(z)\left[c+\theta_{M} b(a+b c)\right]\right\}
$$

Output and prices, as of step 1 and taking into account the choice of the monetary authority at step 4 (a), are

$$
y(z)=\frac{1}{1+\theta_{M} b^{2}}\left[\bar{y}+b\left(\pi_{M}-\pi^{e}\right)+\theta_{M} b^{2} y_{M}+a x(z)\right]
$$

and

$$
\pi(z)=\frac{1}{1+\theta_{M} b^{2}}\left[\pi_{M}-\theta_{M} b\left(\bar{y}-y_{M}\right)+\theta_{M} b^{2} \pi^{e}-\theta_{M} b a x(z)\right]
$$

The private sector sets its expectations rationally at step 3 by taking the expected value of (H.11).

Using (28), (13) and (30), we can solve for output and the price level as a function of the parameters of the model

$$
y(z)=\frac{1}{\theta_{F}+\theta_{M}^{2} b^{2}}\left[\theta_{F} y_{F}+\theta_{M}^{2} b^{2} y_{M}+\theta_{M} b\left(\pi_{M}-\pi_{F}+\int \delta b / a\right)-\delta\left(1+\theta_{M} b^{2}\right) / a\right]
$$

and

$\pi(z)=\frac{1}{\theta_{F}+\theta_{M}^{2} b^{2}}\left[\theta_{F} \pi_{M}+\theta_{M} b \theta_{F}\left(y_{M}-y_{F}\right)+\theta_{M}^{2} b^{2}\left(\pi_{F}-\int \delta b / a\right)+\delta \theta_{M} b\left(1+\theta_{M} b^{2}\right) / a\right]$. 
Substituting the price target (18) into (H.12) and (H.13), one obtains that

$$
\int y=\int y_{F}-\frac{\delta}{\theta_{F} a}, \quad \int \pi=\pi_{F} .
$$

If the central bank is appropriately conservative as in (18), fiscal commitment delivers on average the second-best allocation.

\section{References}

Alesina, Alberto and Guido Tabellini. 1987. "Rules and Discretion with Noncoordinated Monetary and Fiscal Policies." Economic Inquiry, 25(4), October, 619-630.

Banerjee, Gaurango. 1997. Rules and Discretion with Separate Fiscal Authorities and a Common Monetary Authority. Doctoral dissertation. Tuscaloosa, AL: University of Alabama.

Barro, Robert J. and David B. Gordon. 1983. "A positive theory of monetary policy in a natural-rate model." Journal of Political Economy, 91(3), June, 589-610.

Beetsma, Roel M. W. J. and A. Lans Bovenberg. 1998. "Monetary Union without Fiscal Coordination May Discipline Policymakers." Journal of International Economics, 45(2), August, 239-58.

Chari, V-V, Kehoe, Patrick J. and Ellen R. McGrattan. 2000. "Sticky Price Models of the Business Cycle: Can the Contract Multiplier Solve the Persistence Problem?" Econometrica, September. 68(5), 1151-79.

Debelle, Guy and Stanley Fischer. 1994. "How Independent Should a Central Bank Be?" in Goals, Guidelines, and Constraints Facing Monetary Policymakers. ed. Jeffrey C. Fuhrer, Boston, MA: Federal Reserve Bank, pp. 195-221. June.

Dixit, Avinash and Luisa Lambertini. 2000 a. "Symbiosis of Monetary and Fiscal Policies in a Monetary Union." Forthcoming in Journal of International Economics. PDF file at

http://econweb.sscnet.ucla.edu/lambertini/papers/symbiosis.pdf

Dixit, Avinash and Luisa Lambertini. 2000 b. "Fiscal Discretion Destroys Monetary Commitment." Working paper. PDF file at http://econweb.sscnet.ucla.edu/lambertini/papers/fiscdisc.pdf

Dixit, Avinash and Luisa Lambertini. 2001. "Monetary-Fiscal Policy Interactions and Commitment Versus Discretion in a Monetary Union," European Economic Review, 45(4-6), May, 977-87.

Galí, Jordi. 2001. "New Perspectives on Monetary Policy, Inflation, and the Business Cycle," working paper.

Hillier, Brian and James M. Malcomson. 1984. "Dynamic Inconsistency, Rational Expectations, and Optimal Government Policy," Econometrica, 52(6), November, 1437-51. 
Kehoe, Patrick. 1989. "Policy Cooperation among Benevolent Governments May Be Undesirable." Review of Economic Studies, 56(2), April, 289-96.

Kydland, Finn and Edward Prescott. 1977. "Rules Rather Than Discretion: The Inconsistency of Optimal Plans." Journal of Political Economy, 85, 473-490.

Persson, Torsten and Guido Tabellini. 1993. "Designing Institutions for Monetary Stability." Carnegie-Rochester Conference Series on Public Policy, 39(0), December, 53-84.

Rogoff, Kenneth. 1985 a. "The Optimal Degree of Commitment to an Intermediate Monetary Target," Quarterly Journal of Economics, 100(4), November, 1169-1189.

Rogoff, Kenneth. 1985 b. "Can International Monetary Policy Cooperation Be Counterproductive?" Journal of International Economics, 18(3-4), May, 199-217.

Svensson, Lars. 1997. "Optimal Inflation Targets, 'Conservative' Central Banks, and Linear Inflation Contracts." American Economic Review, 87(1), March, 98-114.

Walsh, Carl. 1995. "Optimal Contracts for Independent Central Bankers." American Economic Review, 85, 150-167.

Woodford, Michael. 1999. "Inflation Stabilization and Welfare." Working paper, August. 